\title{
Enhanced Financial Business Competitiveness by Leveraging Technology and Innovation
}

\author{
Suwinto Johan* \\ Management Program, Faculty of Business, President University \\ Jawa Barat 17530, Indonesia \\ Email: suwintojohan@gmail.com
}

\begin{abstract}
The financial industry has developed rapidly with the emergence of financial technology companies. Moreover, the use of technology in the financial industry has developed rapidly. However, conventional financial companies face tough challenges in doing business. They have to adopt the technology to survive. The adoption of technology will increase the competitiveness of established financial companies against financial technology companies. The research aims to analyze the impact of technology on improving the work process of established financial companies. It examines the business model of established financial companies and financial technology companies. The work process is almost identical for all companies. The research applies a qualitative method. The chosen companies are multi-purpose financing for the purchase of two-wheeled and four-wheeled motorized vehicles. The total number of companies involved in the research is four companies. The result concludes that conventional consumer finance companies need to adopt technology into the work process to compete with financial technology companies. Technologies that can be used are Artificial Intelligence (AI), automation job allocation, chatbot, and face recognition. The work process is reviewed by digitizing, eliminating, and moving. Then, technology adoption will require a large investment. Hence, consumer finance companies can collaborate with technology companies, including financial technology companies.
\end{abstract}

Index Terms-Financial Business, Business Competitiveness, Financial Technology, Financial Innovation

\section{INTRODUCTION}

$\mathbf{E}$ FFICIENCY is one of the main criteria in competition in the financial industry. Thus, the financial industry makes various efforts to increase efficiency. The financial industry is a service industry in which humans are the main contributors to it. It is a laborintensive industry. On average, the costs to income ratio reached $198 \%$ in the financial industry [1]. Employee costs increase from year to year in proportion to inflation. The financial service industry growth tends to

Received: Jan. 17, 2021; received in revised form: April 13, 2021; accepted: June 15, 2021; available online: Aug. 30, 2021. *Corresponding Author follow the economic growth of a country. The financial industry supports the growth of the country's economy. Hence, the growth of the financial industry will match inflation growth.

The financial services industry is very competitive. The growth is significant. However, the financial industry experiences a negative spread if the growth is lower than inflation. Inflation will lead to cost growth. Then, higher inflation will result in higher costs than revenue growth. If this situation happens, the financial industry will experience negative growth [2].

The financial services industry has made various efforts to increase efficiency. Various improvement methods have been adopted, such as Business Process Re-engineering (BPR), Enterprise Resources Planning (ERP), Six Sigma $(6 \sigma)$, Total Quality Management (TQM), and Plan Do Check Action (PDCA) [3]. These methods have facilitated the evolution of the financial services industry. Efficiency can be increased gradually. Moreover, according to previous research [4], three strategies can be used: cost leadership strategy, differentiation strategy, and niche strategy. The cost leadership strategy is one of the strategies used by banks in general. Meanwhile, cost leadership strategy is a strategy employed to achieve operational excellence. Then, operational excellence aims to achieve the best work process at an efficient cost.

Furthermore, technology has changed the business model for many industries. A different business model with the existing model has created a different competitive landscape. Changes in the business model in using technology have occurred in the digital transportation industry, trading industry with marketplaces, accommodation industry, and e-commerce. The 'sharing economy' is progressing to change many industries [5]. As a result, financial technology companies have changed the work patterns of the financial industry. Financial technology includes peer-to-peer lending, payment gateways, cryptocurrency, crowdfunding, and others. This change has forced established financial companies to reconsider how to compete with fi- 
Cite this article as: S. Johan, "Enhanced Financial Business Competitiveness by Leveraging Technology and Innovation”, CommIT (Communication \& Information Technology) Journal 15(2), 79-89, 2021.

nancial technology companies. Conventional financial companies view financial technology companies as a competitor. However, the research examines a potential for collaboration between established companies and startup companies. It focuses on financial companies with startups, especially financial technology startups. This kind of research is still rare as the research studies the business models of financial industries with the framework of Industry 4.0.

Financial technology companies rely on technology in competition. With technology, this type of company has become more efficient than established companies. The number of workers is small. Hence, the financial services industry, which is labor-intensive, has become technology-intensive. Many human activities have been replaced by technology [6]. Conventional financial companies also adopt technology into their existing business models. However, technology adoption is a challenge for established financial companies. In addition, culture becomes one of the challenges. There are very few studies on increasing the competitiveness of financial companies by using technology. The research discusses work processes that can be altered with technology. This change will increase the competitive ability of established financial companies.

Moreover, big corporations increasingly create partnerships with startups to speed up their improved development, and researchers emphasize the prospects of such partnerships to improve innovations [7]. In current years, the phenomenon of open innovation has been growing in conventional businesses, especially in partnership with startup firms [8]. Nowadays, the alliance between large companies and startups has become a trending partnership. Large companies need startup's human resources. Meanwhile, startup companies need funding and flexibility from large conventional financial companies. The collaboration will create value for both companies. Inventing value for consumers and shareholders is not two entirely different objectives, as the business surge and executives fear. The innovation can produce value for stockholders by pleasing consumers [9]. Innovation and collaboration are ways to increase company value.

However, the management of established financial companies experiences difficulties in changing existing work patterns. Changing work patterns with the existing workforce is not easy to do. Competition from financial technology faces a lack of funding. Hence, the research also provides a work process proposal to improve its competitive ability. There are very few researchers on cooperation between established companies and startups, especially in the financial industry, so the research will bring insights to both academics and businesses.
The research is conducted in a country with the fourth-largest population in the world, Indonesia. In Indonesia, the number of conventional finance companies is more than 200 companies and 100 banks [10]. The research is interesting for industries in developing countries.

\section{A. Transaction Cost Economic Theory}

Transaction Cost Economics (TCE) theory is one of the most widely referenced organization development theories in operation and supply chain management research. It is essentially a principle of efficient governance of transactions in particular and exchange relationships in general [11]. It is an efficiency theory used by companies in creating competitiveness. It has been used in the integration of similar companies. Its goal is to create a competitive cost structure [12].

The concept of the transactional nature of blockchain technology and TCE suggests a standard to prove why and how blockchain technology-based applications are useful. The model tries to demonstrate how blockchain technology can be utilized to overcome numerous problems in-built in startup financing firms [13].

For example, by revising business models to handle the recent competitive challenges modeled by sharing platforms, hotel industries can influence their greater capacity to deal with three crucial features of businesses drawn from Transaction Cost Theory (TCT) (frequency, uncertainty, and asset specificity) and improve 'integrated platforms'. By employing the TCT, previous research develops a method to analyze how transaction features influence the development of sharing platforms [5]. Hence, it has clear implications for businesses that are impacted by these improvements, not least the hotel business.

\section{B. Continuous Process Improvement}

The work process improvement process starts with systematic improvement. It is called continuous improvement. Improvement of work processes occurs with internal resources or collaboration with external parties. External parties can be more and more efficient than internal parties.

A basic hypothesis of Business Process Management (BPM) is that restructuring delivers refined and enhanced versions of business processes [14]. Process Improvement (PI) is a continuous action in performing operational activities. Every procedure is estimated to be enhanced to accomplish endless improvement. Then, process improvement can diminish cycle time [15].

Moreover, reshaping business processes has an enormous potential in cutting costs and improving the 
Cite this article as: S. Johan, "Enhanced Financial Business Competitiveness by Leveraging Technology and Innovation”, CommIT (Communication \& Information Technology) Journal 15(2), 79-89, 2021.

satisfaction of customers. The level of organization creates structural coordination and motivation, which will influence the success of the PI project following the mediating constructions of alignment, routinization, and embeddedness, specifically in the financial services industry.

\section{Collaboration}

"We cannot solve our problems by with the same way that we used when the problems were formed," as said by Albert Einstein (1879-1955). Collaboration is a contemporary mantra of the neo-liberal academia and part of a discourse related to the study of quantitative performance, which is measured by co-authorship. Outside the metrics and positive rhetoric, collaboration is paradoxical and complicated [16].

Collaborative connections between new ventures and startup firms by concentrating on value creation in such connections arise when the involved parties exchange assets. For example, collaboration fosters the flows of passive knowledge and the creation of active knowledge. Furthermore, the collaboration delivers new business with access to the complementary assets of the incumbent. Meanwhile, the creation of value gives prospects for valuable capture by both parties. The startup's value capture is determined by its knowledge of the appropriation regime and social capital [17].

To support the collaborative progress of innovative clarifications, constructing links between new ventures and small-medium enterprises recognizes possible users with new know-how, is more accessible to new ventures, and creates new ventures that are more recognizable by SMEs [18]. The latest open collaboration and innovation phenomenon has been on the upsurge in starting firms, especially in collaboration with new ventures. It has the views of both incumbents and startups, along with the outlooks of external experts [8].

Open innovation-collaboration with technology startups is interesting, substantial interest among big companies worldwide. It is a taxonomic context for corporate venture capital acquisitions and mergers, business incubators, procurement, business accelerators, corporate firm builders, co-working areas, startup platform applications, and laboratories innovation. It marks their created features on a predefined set of metrics (strategy, startup target, financing, startup target, culture, structure, resources, measurement of performance, and ecosystem leverage) [19].

Financial technology startups are essential drivers of innovation in the financial sector. Previously, financial technology companies and banks consider each other as competitors. However, their focus has shifted towards collaboration, and the rate of collaboration between financial technology companies and banks increases. However, challenges in collaboration still exist [20].

\section{Innovation}

Public listed companies in external capitaldependent businesses create patents of greater quantity, novelty, and quality compared to private firms. Meanwhile, publicly listed firms in internal capitaldependent businesses do not have a considerably better profile in innovation than matched private companies. Public listing is valuable to a firm's innovation in industries with a more significant requirement for external capital [21]. Heterogeneous boards have positive and negative effects on innovation. It is found that ethnic, tenure heterogeneity, and gender inspire companies to invent [22].

Innovation is a crucial variable in the relationship between financial and social performance of a corporation. It allows organizations to react to new social, economic, and environmental challenges better and faster than organizations that cannot innovate. Consequently, the investment of the financial resources in innovation creativities is one of the most crucial levers to pursue and increase the social performance of a corporation [23].

The technological innovation competence in acquiring a company positively intervenes in the relationship between performance and business ties of crossborder mergers and acquisitions. Then, turbulence in the environment moderates the relationship between technological innovation competence and business ties. However, cultural distance negatively moderates the relationship between the performance of cross-border mergers and acquisitions and technological innovation competence. The previous research shows that mutual funds' holdings significantly increase firm innovation in Chinese listed companies. However, grey institutional holdings (including insurance companies and pension funds) and Qualified Foreign Institutional Investor (QFII) holdings have less or no significant influence on innovations. It includes controlling for firm financial performance, regions, listing board, firm governance, and possible endogeneity [24]. Then, green product innovation arbitrates the connection between green process innovation and the financial performance of a firm. The firm's green social image regulates the relationship between financial performance and green product innovation [25].

The innovation strategy has a critical influence on the performance of the businesses [26]. Investing in Research and Development (R\&D), size of the firm, 
Cite this article as: S. Johan, "Enhanced Financial Business Competitiveness by Leveraging Technology and Innovation", CommIT (Communication \& Information Technology) Journal 15(2), 79-89, 2021.

formal training, the status of exporting, type, location, competitors, sector, or activity of firms all positively determine a firm's propensity to innovate [27]. Moreover, the process of innovation stimulates radical and incremental product innovation. There are several variances between low-tech and high-tech industries in the moderating effect of organizational innovation and marketing. For high-tech businesses, the relationship between firm performance and a new product is improved with marketing. In low-tech firms, the innovation process has positive and direct influences on a firm's performance with organizational innovation. It shows that synergy effects of innovation exist and can be changed depending on the innovativeness stages and industrial types [28].

Then, foreign company ownership has a positive and causative effect on companies' innovation. Foreign organizations act as active monitors, provide protection for firm managers against innovation failures, and encourage knowledge-sharing from highinnovation economies [29]. Moreover, it has a better comprehension of innovation funding circumstances that the traditional financial way of thinking does not serve [30]. Favorable employee conduct increases innovation focus on innovation projects which are connected to firms' main business [31].

The inter-organizational learning process, open innovation literature, and corporate venture capital demonstrate how the resource knowledge breadth and depth available in a portfolio of external organizations with new ventures cooperate to influence the innovation of a firm [32]. The financial capital and size of a firm mediate and moderate the innovation impact on the performance of the firm, negatively or positively. Decisionmakers state the significance of financial resources and firm size in preparation to present innovations to improve company performance [33].

\section{E. Artificial Intelligence (AI)}

Artificial intelligence (AI) is vital know-how that supports daily life and economic activities. AI has been considered a key for evolution in industrialized countries, such as Europe and the United States, and emerging nations like China and India. The attentiveness has been concentrated mainly on emerging new AI in Information Communication Technology (ICT) and Robot Technology (RT) [34]. Then, there are three types of AI: process automation, cognitive insight, and cognitive engagement. AI can improve outcome functioning, make the staff more innovative, improve internal business processes, and create new products [35]. AI has performed an increasingly enormous function in the economy, and this trend is

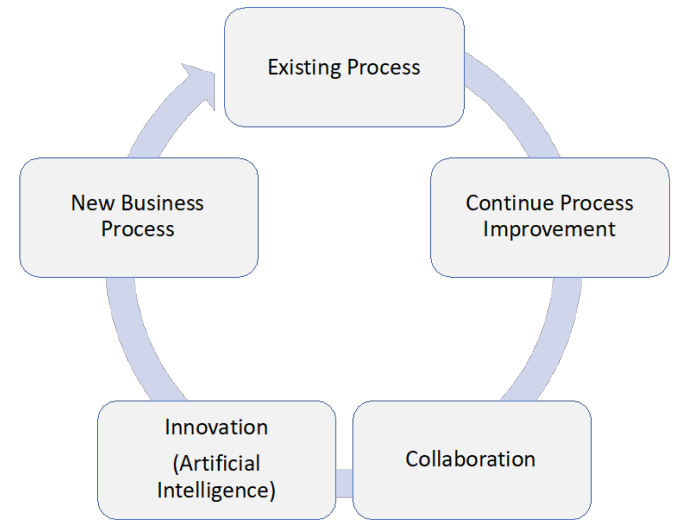

Fig. 1. Reinventing business process wheel.

expected to remain. AI also affects the advancement of the economic system and financial law [36]. It integrates financial data with technology competencies and accelerates the digital revolution of finance to create a safer economic and business environment and reduce human failures [37]. Then, financial companies and non-financial institutions, and governments across the globe embrace and increase the use of AI instruments and functions as they present benefits to certifying the vulnerable groups of people who are not financially active to participate in the formal financial market with minimum challenges and maximum benefits [38]. The process from existing process to new business process is shown in Fig. 1.

\section{RESEARCH METHOD}

The research applies a qualitative method. Qualitative research is based on practical experience or action research combined with a case study. The qualitative technique enables the scholar to discover and better comprehend the difficulty of a phenomenon. Qualitative research has more complexities than quantitative research as it is related to human actions and mind [39]. The research can be categorized as action research related to case studies. Action research is conducted by directly studying the improvement and implementation that have been done. Case studies are only powerful when expanding or verifying well-known concepts or stimulating a specific theory [40]. The research aims to change the existing process or business model in connection with technology development. Changes in business models are based on existing knowledge and theories or concepts. It examines the business model of established financial companies and financial technology companies. The results provide solutions to the established financial companies in competing with financial technology. The advantages of a technology 
Cite this article as: S. Johan, "Enhanced Financial Business Competitiveness by Leveraging Technology and Innovation", CommIT (Communication \& Information Technology) Journal 15(2), 79-89, 2021.

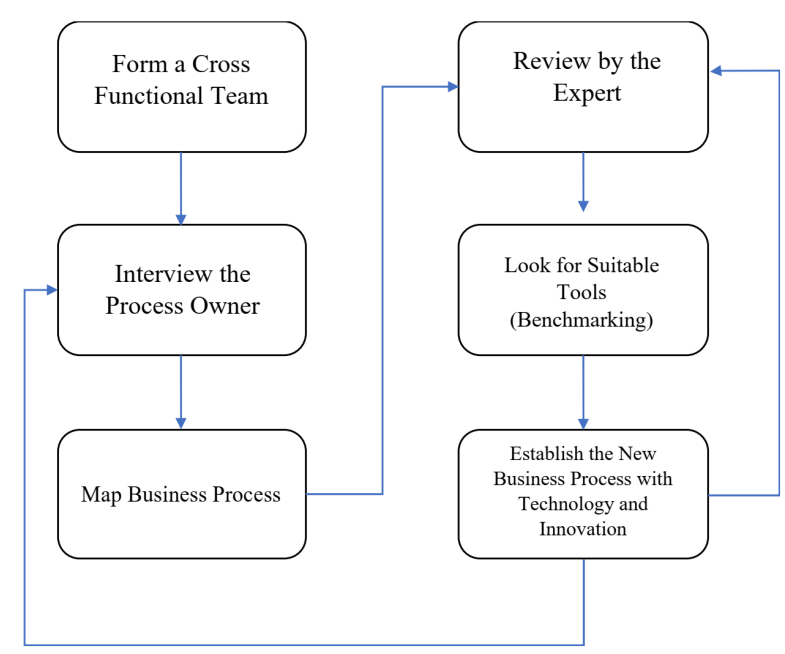

Fig. 2. Improvement process.

company can be added to the business model of a conventional financial firm.

The research conducts interviews with top management in financial technology and established financial companies. The purpose of this interview is to understand the work processes that exist in both types of companies. It is expected to provide a collaborative solution between conventional financial institutions and financial technology. Meanwhile, the action research is an emergent review process that combines concept and act to a systematic knowledge with existing organizational understanding and addresses real organizational difficulties and the people of the system under inquiry. This method has a complex history because it is not a specific theoretical study but a research method that has been developed over time through a wide range of studies [41]. It is a qualitative research type that demands an action to develop a practice and study the effects of such actions.

The research is conducted on consumer finance companies. The companies are multi-purpose financing for the purchase of two-wheeled and four-wheeled motorized vehicles. There are four companies in the research. The work processes of all companies are almost identical. Therefore, there is no case-by-case separation in the discussion for each company. The process improvement process is described in Fig. 2.

\section{RESUlTS AND Discussion}

The creation of a new business model reviews the necessary work processes. The necessary work processes will be made easier with technology and innovation. Meanwhile, unnecessary work processes will be merged or eliminated.

\section{A. Simplify Work Process}

The work process in existing business models is reviewed. Management must consider the existing work process if it is essential. If the work process is needed, the work process must be digitized. If the work process cannot be digitized, it needs to be considered to be transferred or collaborated with other parties who have more expertise in carrying out this work process. This transfer will make the company more efficient. The transfer is a form of collaboration with other companies.

However, if the work process is not required, the work process must be eliminated. Elimination can be done by removing or combining with other processes. Thus, the company's work process becomes more efficient. The concept of Digitize, Eliminate, and Move (DEM) will create a new work process. Then, the new work process will create a new business model.

The primary consideration for using the DEM concept is the transaction cost. Implementing DEM can save costs on repetitive processes. The concept makes the process more efficient. Moreover, the DEM concept also considers continuous improvement and collaboration with startup companies. The use of new technology using AI replaces human resources. Hence, this change in the work business has resulted in new business model innovations.

Besides, DEM can define clear responsibilities on the department in charge. However, it creates a department or individual-centric effect. The process will depend on a single department or person. Then, DEM can be implemented in making reports. Companies produce much information, but not all pieces are needed in making decision process. Eliminating the report or 
Cite this article as: S. Johan, "Enhanced Financial Business Competitiveness by Leveraging Technology and Innovation”, CommIT (Communication \& Information Technology) Journal 15(2), 79-89, 2021.

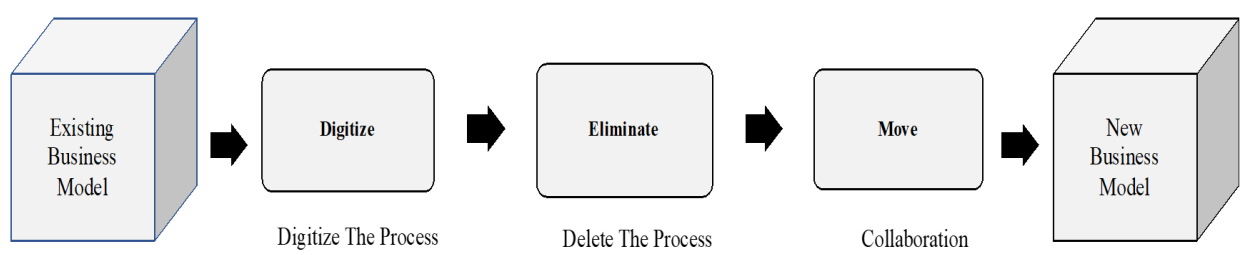

Fig. 3. Digitize, Eliminate, and Move (DEM) concept.

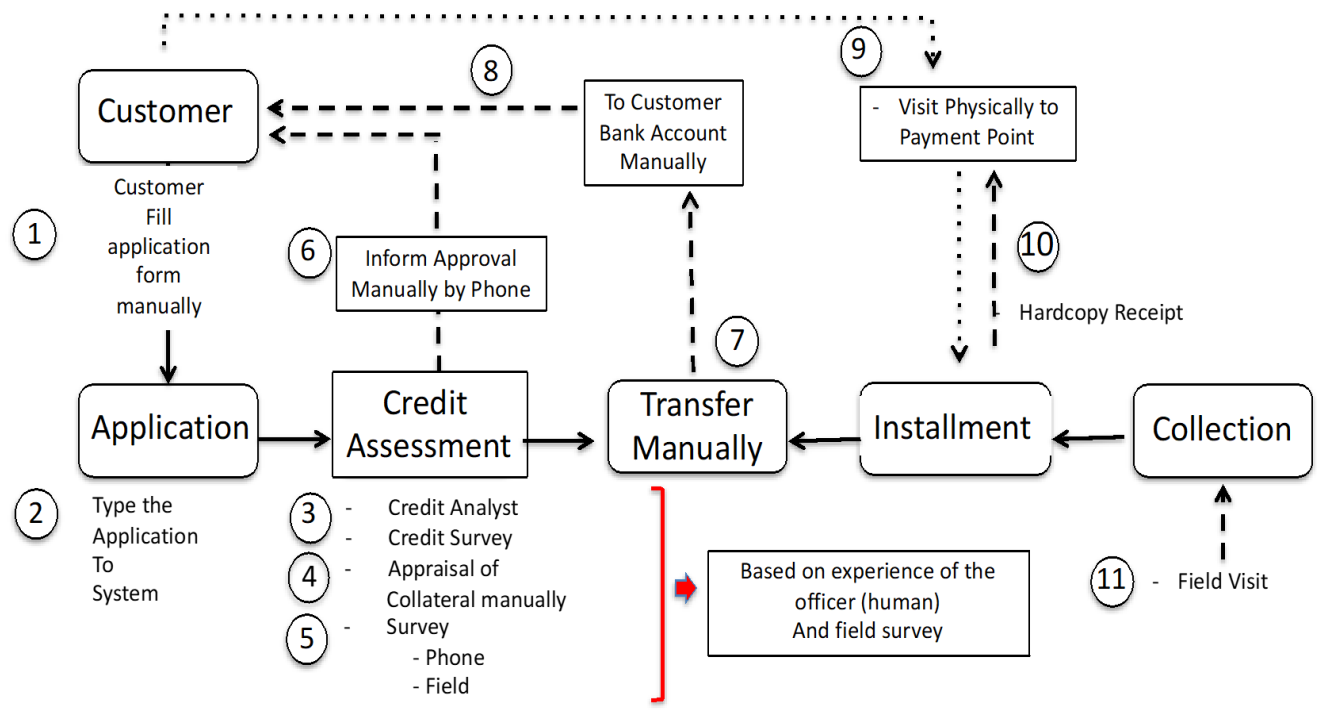

Decentralize : Appraisal, Credit / Tele-Survey, Tele-Credit, Tele-Collection

Fig. 4. Existing business process.

moving the report to the correct section will save a lot of time and money. This DEM concept is depicted in Fig. 3.

\section{B. Changes in Business Model}

In the existing business process (see Fig. 4), customers submit credit applications by filling out the form manually. They provide the necessary data, such as financial data, personal data, and others. Then, administrative staff submits the data into the system manually. With this system, the data are sent to a credit analyst. Next, credit analysts will review credit quality and verify customer data.

Similarly, the surveyor will verify the collateral provided. Verification is done manually. From all the data, the credit analyst will decide the approval of the application. Then, submission of approval will be submitted to the credit committee. This process is done semi-manually. Moreover, decisions are submitted into the system semi-manually. Decisions are based on the experience and knowledge of each credit committee member.

Then, credit approval is informed to the customers manually by calling or informing them directly. After that, the customer must sign the agreement at the financial institution's office. After all the processes are done, documents are complete, and the collateral will be provided. All data regarding customers and guaranteed items are manually rechecked in this process. The financial institution will send the borrowed fund to the customers' bank accounts as mentioned in the credit application form. This transfer of funds is done manually by the finance department in head office. After the disbursement of funds, the customers' relationship with the financing institution begins. The customer will pay monthly installments at the branch of the financial institution. Proof of payment is given in hardcopy to the customer.

If the customers do not make a payment, the billing will be made. Billing provides notification of debt maturity. Collection warning letters will be issued up 
Cite this article as: S. Johan, "Enhanced Financial Business Competitiveness by Leveraging Technology and Innovation", CommIT (Communication \& Information Technology) Journal 15(2), 79-89, 2021.

TABLE I

IMPROVEMENT INITIATIVE.

\begin{tabular}{clll}
\hline No. & Project & Improvement & Initiative \\
\hline 1 & Application Documents & Scan or input directly by using a mobile application & Digitize and move \\
2 & Appraisal & Virtual appraisal by using video/teleconference & Digitize \\
3 & Survey & Smart survey by using Global Positioning System & Digitize and eliminate \\
4 & Centralization and Job Allocation on & (GPS), TeleCheck, and auto job allocation & Leveraging AI in mapping and auto job assignment/al- \\
& Survey & location & Digitize \\
5 & Credit Scoring & AI in making credit approval & Digitize and move (human factors) \\
6 & Behavior Scoring & AI in determining the type of customer and type of & Digitize and move (human factors) \\
7 & Disbursement & follow-up for an overdue customer & Digitize and move (collaboration) \\
8 & Collection & E-wallet and automation & Digitize \\
9 & Collection & Centralized collection and auto job allocation & Digitize \\
10 & Branch Model & Territory management & Digitize \\
11 & Signing Agreement & Smart model (face recognition) linked to mobile appli- & Digitize \\
\hline
\end{tabular}

to three times. This submission is also made manually. The collector will ask for payment by visiting the customers' domicile and delivering the warning letter.

Credit, verification, and collection activities are carried out in a decentralized manner. The branches at the location perform these activities. This decentralization increases costs and inefficient processes with the non-standard process and requirement of human justification. With the standard process, the processes can be centralized and standardized. Based on the work process in Fig. 4, established financial companies and financial technology companies can create improvements based on the DEM concept, continuous improvement, innovation, and collaboration. The company can identify each work process and take improvement initiatives to create new work processes. Each project identifies the types of improvements that can be made. For example, the eleventh work process in Fig. 4 can be digitized. With this digital process, work processes can be saved with a single input. A single input can create data consistency and data integrity. Then, consumers can submit data by typing or scanning documents using a camera on the mobile phone. The incoming data will not be faulty. In Table I, these projects are described, and improvement projects are detailed.

For the improvement, the established financial companies can do several things. First, surveyors' appraisal uses video conferencing and digital maps. Digital mapping of the location of the house is done by sending the Global Positioning System (GPS). Therefore, the position of the house is precise than the manual location drawing a picture. Second, automation job allocation will also make the use of labor more efficient. It is equal to fieldwork and job centralization. The work process becomes faster and more efficient. Third, credit decisions are made using AI. Credit decisions in the form of scoring with machine learning are based on existing customers' experiences. Hence, credit decisions have become more objective than formerly subjective decisions.

Fourth, disbursement is carried out through an endto-end system with other banks. If the credit is approved, the customers will receive the funds shortly. Delivery of funds can also be made to the customer's e-wallet. Fifth, behavior scoring can also be done in determining the handling of late-paying customers. Not all customers need to be reminded of the process in these stages, but they may also need to be reminded. The reminder can use a messaging application than a phone call. It can be created automatically by the system. Sixth, customers' identity cards will be replaced by face recognition. Previously, the customers take care of all things with their identity cards. Now, branches of financial institutions can use customers' face recognition.

Changes in this business model can create the company more efficient and effective. This change in the business model will apply a low-cost producer strategy for the companies. The new business model has a high dependence on a Machine to Machine (M2M) communication. However, if there is a problem with the engine, the process will be crashed from the front end to the back end. It can create a significant potential loss. Moreover, changing work patterns to digital will save costs, such as paper costs, the potential for data input errors, and repetitive processes. Labor costs, paper costs, electricity costs, and others will be reduced significantly.

\section{Artificial Intelligence (AI)}

The innovation in business processes has changed the business model from manual and human dependent to a digital business model. The digital business model will shorten the work process to be more efficient and take a shorter cycle time. For example, the credit 
Cite this article as: S. Johan, "Enhanced Financial Business Competitiveness by Leveraging Technology and Innovation”, CommIT (Communication \& Information Technology) Journal 15(2), 79-89, 2021.

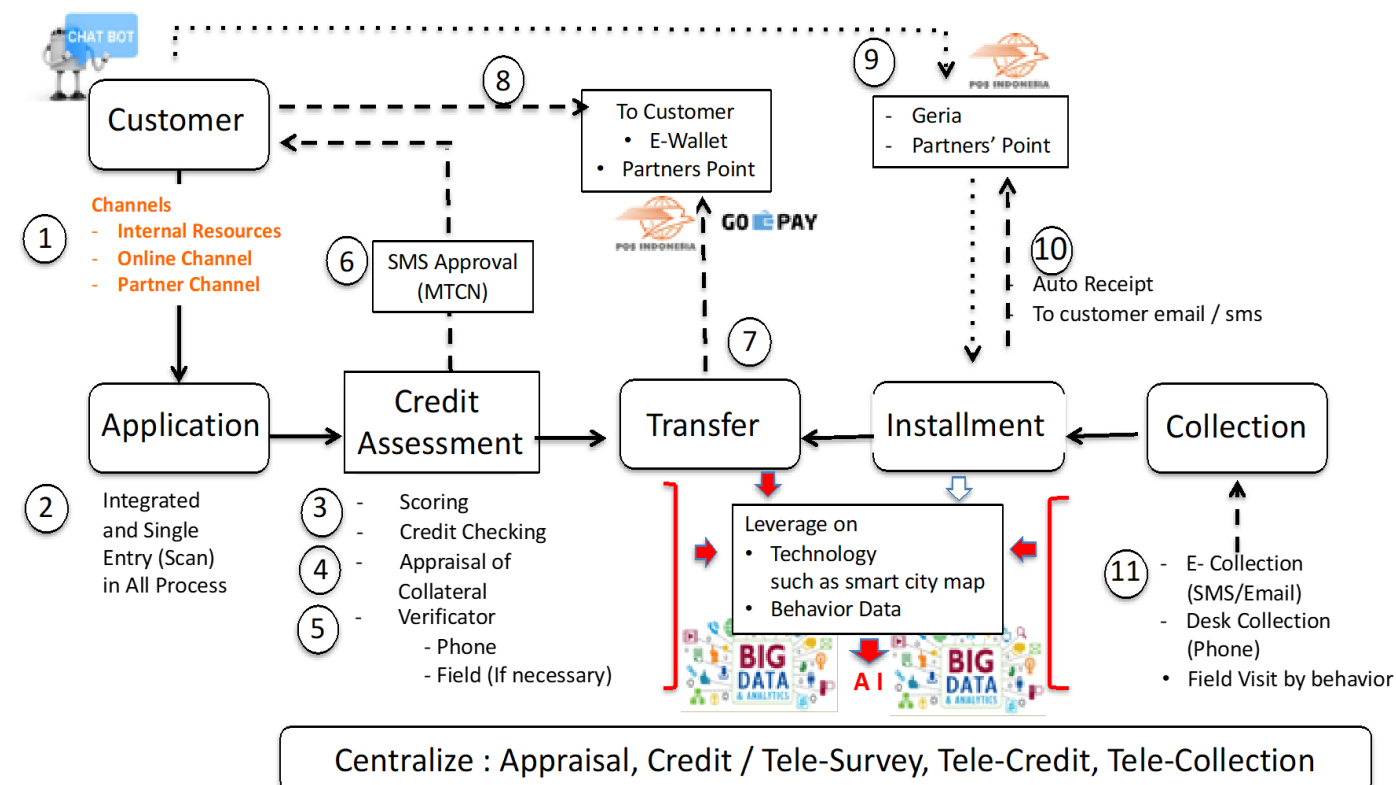

Fig. 5. New digital business process.

approval is reduced from 8 hours to 4 hours, and the cost-saving can be more than $50 \%$. The new business model is depicted in Fig. 5.

However, the companies themselves cannot do this business process transformation. The company must collaborate with startup companies. Companies will have difficulty building face recognition systems, chatbots, mobile applications, automation job allocation, e-wallet, end-to-end systems, payment points, AI for credit scoring and behavior scoring, and others. Thus, conventional financial companies need to cooperate with startup companies that already have the ability to implement these technologies.

The new digital business process provides a new system. First, AI will replace credit approval by humans. It also replaces the billing handling that is carried out for all late-paying customers and the equation. As a result, different handling will create efficiency. Second, the chatbot is developed to replace handling customer voice. Customer service is only for issues that a chatbot cannot answer. Thus, the number of existing customer services will be reduced. Third, face recognition will replace the customers' identity cards. With this face recognition, a valid customer will be more precise than the identity card that has the possibility of being faked. Fourth, the mobile application will replace the existing system on the hardware or computer. The mobile application can be used on the mobile phone. Documents can be scanned using a mobile camera application. Thus, the company can save on investment in hardware and human resources. Fifth, automation job allocation can help humans to allocate resources so that the number of workers becomes more productive than before. Sixth, e-wallet and payment systems will replace the conventional bank transfer system, as stated in Fig. 5.

In the credit approval process and work processes, AI will provide fair and objective credit decisions and work processes. Decision-making will also be faster than before. However, it will result in dependence on artificial intelligence (AI). Decisions in humans become less accurate and sharp because of the application of AI. Besides, the determination of parameters in AI is essential. Then, the completeness of data is crucial because of the principle of garbage in and garbage out. Moreover, Indonesia does not have centralized data. On the other hand, the use of AI in credit decisions will reduce the potential for credit default losses. The savings in credit costs will be very significant and will increase the value of the company.

With technology and innovation in Table II, the established financial companies are efficient and can compete with financial technology companies. Meanwhile, with technology, established financial companies can make more informed and standardized decisions. In developing this technology, established financial companies must collaborate with startup companies to achieve maximum results. Conventional financial companies will find it challenging to develop their technology. 
Cite this article as: S. Johan, "Enhanced Financial Business Competitiveness by Leveraging Technology and Innovation”, CommIT (Communication \& Information Technology) Journal 15(2), 79-89, 2021.

TABLE II

TECHNOLOGY OR INNOVATION IN FINANCIAL SERVICES.

\begin{tabular}{cll}
\hline No. & Technology & Function \\
\hline 1 & AI & Credit approval and handling collection \\
2 & Chatbot & Customer service and response to a cus- \\
3 & Face Recognition & Customer identification \\
4 & Mobile Application & Input data \\
5 & Job Allocation & Resource allocation \\
6 & E-Wallet & Payment system \\
7 & Digital Signature & Paperless documentation \\
8 & Digital Receipt & Paperless documentation \\
\hline
\end{tabular}

\section{CONCLUSion}

Collaboration between established financial companies and startups is a must. Established companies can survive in competition with financial technology companies if they collaborate with technology startup companies. The collaboration to create a new business model will provide added value to the company and stakeholders. The research is conducted at consumer finance companies in Indonesia, a country with the world's fourth-largest population. However, the research can also be established in developed countries that have better data collection systems. It can also be conducted in countries that are more advanced in terms of annual income. In summary, the research also provides an overview for regulators to encourage cooperation between established financial companies and startups. They can also implement regulations by enforcing cooperation between them. Management can learn new business model development to develop cooperation by using digitizing, eliminating, and moving.

The research has limitations in obtaining information about business processes. The companies studied are still keeping their business processes secret. Moreover, there are also limitations in terms of case-by-case discussion. A research with a larger sample is needed. Then, future research can use the Digitize Eliminate Move (DEM) method in other financial industry processes besides the consumer finance industry. Future research on collaboration between technology companies and other economic sectors can be developed.

\section{REFERENCES}

[1] S. Johan, "Performance and contribution of Japanese and non-Japanese financial institutions in developing economies: An empirical research in Indonesia," JDM (Jurnal Dinamika Manajemen), vol. 11, no. 1, pp. 56-64, 2020.

[2] — - "Analisis struktur industri pembiayaan Indonesia," Jurnal Muara Ilmu Ekonomi dan Bisnis, vol. 1, no. 1, pp. 18-25, 2017.
[3] Y. S. Cho and K. Linderman, "Metacognitionbased process improvement practices," International Journal of Production Economics, vol. 211, pp. 132-144, 2019.

[4] S. Johan, "Implementasi strategi bisnis dan korporasi melalui merger dan akuisisi," Ultima Management: Jurnal Ilmu Manajemen, vol. 3, no. 1, pp. 68-81, 2011.

[5] Y. H. Akbar and A. Tracogna, "The sharing economy and the future of the hotel industry: Transaction cost theory and platform economics," International Journal of Hospitality Management, vol. 71, pp. 91-101, 2018.

[6] Y. M. A. Amuna, S. S. Abu-Naser, M. J. Al Shobaki, and Y. A. A. Mostafa, "Fintech: Creative innovation for entrepreneurs," International Journal of Academic Accounting, Finance and Management Research (IJAAFMR), vol. 3, no. 3, pp. 8-15, 2019.

[7] M. P. Allmendinger and E. S. Berger, "Selecting corporate firms for collaborative innovation: Entrepreneurial decision making in asymmetric partnerships," International Journal of Innovation Management, vol. 24, no. 01, pp. $2050003-1-$ $2050003-2,2020$.

[8] J. K. De Groote and J. Backmann, "Initiating open innovation collaborations between incumbents and startups: How can David and Goliath get along?" International Journal of Innovation Management, vol. 24, no. 02, pp. $2050011-1-$ 2050011-33, 2020.

[9] G. Rubera and A. H. Kirca, "You gotta serve somebody: The effects of firm innovation on customer satisfaction and firm value," Journal of the Academy of Marketing Science, vol. 45, no. 5, pp. 741-761, 2017.

[10] Otoritas Jasa Keuangan, "Statistik lembaga pembiayaan periode Desember 2020," 2021. [Online]. Available: https://bit.ly/3xXsbU7

[11] M. Ketokivi and J. T. Mahoney, "Transaction cost economics as a theory of supply chain efficiency," Production and Operations Management, vol. 29, no. 4, pp. 1011-1031, 2020.

[12] S. Johan, "Determinant efficiency of financial institutions in emerging market," Jurnal Manajemen dan Pemasaran Jasa, vol. 12, no. 2, pp. 165-176, 2019.

[13] S. Ahluwalia, R. V. Mahto, and M. Guerrero, "Blockchain technology and startup financing: A transaction cost economics perspective," Technological Forecasting and Social Change, vol. 151, pp. 1-6, 2020.

[14] S. Satyal, I. Weber, H. Y. Paik, C. Di Ciccio, 
Cite this article as: S. Johan, "Enhanced Financial Business Competitiveness by Leveraging Technology and Innovation”, CommIT (Communication \& Information Technology) Journal 15(2), 79-89, 2021.

and J. Mendling, "Business process improvement with the AB-BPM methodology," Information Systems, vol. 84, pp. 283-298, 2019.

[15] I. Taifa and T. Vhora, "Cycle time reduction for productivity improvement in the manufacturing industry," Journal of Industrial Engineering and Management Studies, vol. 6, no. 2, pp. 147-164, 2019.

[16] B. Macfarlane, "The paradox of collaboration: A moral continuum," Higher Education Research \& Development, vol. 36, no. 3, pp. 472-485, 2017.

[17] V. Aggarwal and A. Wu, "Inter-organizational collaboration and start-up innovation," in Entrepreneurship and collaboration, S. Matusik and J. Reuer, Eds. Oxford, UK: Oxford University Press. Forthcoming, 2018, pp. 1-26.

[18] F. Mercandetti, C. Larbig, V. Tuozzo, and T. Steiner, "Innovation by collaboration between startups and SMEs in Switzerland," Technology Innovation Management Review, vol. 7, no. 12, pp. 23-31, 2017.

[19] L. Peter, A. Back, and T. Werro, "A taxonomic framework on prevalent collaborative innovation options between corporations and startups," International Journal of Digital Technology \& Economy, vol. 3, no. 2, pp. 63-94, 2018.

[20] A. Gviniashvili, "Collaboration for innovation in the financial sector: A qualitative study of Norwegian FinTechs," Master's thesis, TIK Center for Technology, Innovation and Culture, Faculty of Social Sciences, University of Oslo, 2019.

[21] V. Acharya and Z. Xu, "Financial dependence and innovation: The case of public versus private firms," Journal of Financial Economics, vol. 124, no. 2, pp. 223-243, 2017.

[22] S. Munir, G. J. Rangel, R. K. Subramaniam, and M. Z. Bin Mustapha, "Do heterogeneous boards promote firm innovation? Evidence from Malaysia," Capital Markets Review, vol. 28, no. 1, pp. 25-47, 2020.

[23] P. Ruggiero and S. Cupertino, "CSR strategic approach, financial resources and corporate social performance: The mediating effect of innovation," Sustainability, vol. 10, no. 10, pp. 1-22, 2018.

[24] J. Chi, J. Liao, and J. Yang, "Institutional stock ownership and firm innovation: Evidence from China," Journal of Multinational Financial Management, vol. 50, pp. 44-57, 2019.

[25] X. Xie, J. Huo, and H. Zou, "Green process innovation, green product innovation, and corporate financial performance: A content analysis method," Journal of Business Research, vol. 101, pp. 697-706, 2019.
[26] F. Ezzi and A. Jarboui, "Does innovation strategy affect financial, social and environmental performance?" Journal of Economics, Finance and Administrative Science, vol. 21, no. 40, pp. 1424, 2016.

[27] M. Abdu and A. Jibir, "Determinants of firms innovation in Nigeria," Kasetsart Journal of Social Sciences, vol. 39, no. 3, pp. 448-456, 2018.

[28] R. Lee, J. H. Lee, and T. C. Garrett, "Synergy effects of innovation on firm performance," Journal of Business Research, vol. 99, pp. 507-515, 2019.

[29] H. Luong, F. Moshirian, L. Nguyen, X. Tian, and B. Zhang, "How do foreign institutional investors enhance firm innovation?" Journal of Financial and Quantitative Analysis, vol. 52, no. 4, pp. 1449-1490, 2017.

[30] J. Sierra, "How financial systems and firm strategy impact the choice of innovation funding," European Journal of Innovation Management, vol. 23, no. 2, pp. 251-272, 2020.

[31] C. X. Mao and J. Weathers, "Employee treatment and firm innovation," Journal of Business Finance \& Accounting, vol. 46, no. 7-8, pp. 977-1002, 2019.

[32] A. Wadhwa, C. Phelps, and S. Kotha, "Corporate venture capital portfolios and firm innovation," Journal of Business Venturing, vol. 31, no. 1, pp. 95-112, 2016.

[33] P. Kijkasiwat and P. Phuensane, "Innovation and firm performance: The moderating and mediating roles of firm size and small and medium enterprise finance," Journal of Risk and Financial Management, vol. 13, no. 5, pp. 1-15, 2020.

[34] H. Lu, Y. Li, M. Chen, H. Kim, and S. Serikawa, "Brain intelligence: Go beyond artificial intelligence," Mobile Networks and Applications, vol. 23, no. 2, pp. 368-375, 2018.

[35] T. H. Davenport and R. Ronanki, "Artificial intelligence for the real world," Harvard Business Review, vol. 96, no. 1, pp. 108-116, 2018.

[36] L. D. Wall, "Some financial regulatory implications of artificial intelligence," Journal of Economics and Business, vol. 100, pp. 55-63, 2018.

[37] N. R. Mosteanu, "International financial markets face to face with artificial intelligence and digital era," Theoretical \& Applied Economics, vol. 26, no. 3, pp. 123-134, 2019.

[38] D. Mhlanga, "Industry 4.0 in finance: The impact of Artificial Intelligence (AI) on digital financial inclusion," International Journal of Financial Studies, vol. 8, no. 3, pp. 1-14, 2020.

[39] H. K. Mohajan, "Qualitative research method- 
Cite this article as: S. Johan, "Enhanced Financial Business Competitiveness by Leveraging Technology and Innovation”, CommIT (Communication \& Information Technology) Journal 15(2), 79-89, 2021.

ology in social sciences and related subjects," Journal of Economic Development, Environment and People, vol. 7, no. 1, pp. 23-48, 2018.

[40] J. Oh and I. Shong, "A case study on business model innovations using Blockchain: Focusing on financial institutions," Asia Pacific Journal of Innovation and Entrepreneurship, vol. 11, no. 3, pp. 335-344, 2017.

[41] M. Brydon-Miller, D. Greenwood, and P. Maguire, "Why action research?" Action Research, vol. 1, no. 1, pp. 9-28, 2003. 